\title{
ИССЛЕДОВАНИЕ ОТХОДОВ ОБОГАЩЕНИЯ КАМЕННОГО УГЛЯ С ЦОФ «БЕРЕЗОВСКАЯ»
}

\author{
Головачев Андрей Алексеевич \\ магистрант \\ Научный руководитель: Черкасова Татьяна Григорьевна \\ д.х.н., профессор \\ ФГБОУ ВО «Кузбасский государственный \\ технический университет имени Т.Ф. Горбачева»
}

\begin{abstract}
Аннотация. Изучены состав отходов обогащения угля с АО ЦОФ «Березовская». Установлено, что промпродукт и флотационный кек, образующиеся в результате обогащения угля, содержат в себе большое количество неизвлеченного угля, который можно использовать в качестве топлива. Минеральная часть отходов состоит из матричных элементов, находящих широкую область применения в строительстве, а также содержит в себе большое количество микрокомпонентов редких и ценных металлов.
\end{abstract}

Ключевые слова: каменный уголь, отходы обогащения угля, тяжелосредная сепарация, отсадка, флотация, порода, промпродукт, кек, зольность, химический состав золы.

\section{RESEARCH OF COAL PROCESSING WASTE FROM THE PROCESSING PLANT «BEREZOVSKAYA»}

\author{
Golovachev Andrey Alekseevich \\ Scientific adviser: Cherkasova Tatiana Grigorievna
}

\begin{abstract}
The composition of coal enrichment waste from the processing plant "Berezovskaya" has been studied. It has been established that industrial products and flotation products formed as a result of coal enrichment contain a large amount of untreated coal, which can be used as fuel. The mineral part of the waste consists of matrix elements that are widely used in construction, and also contains a large number of micro-components of rare and valuable metals.
\end{abstract}


Keywords: coal, coal enrichment waste, heavy-medium separation, deposition, flotation, rock, industrial product, cake, ash content, chemical composition of ash.

Вопросы экологии в Кузбассе, являющимся главным угольным регионом России и перегруженном промышленными предприятиями, имеют первостепенное значение. При использовании угля, в частности, на предприятиях теплоэнергетики, образуется огромное количество отходов. Золоотвалы постоянно пылят, химические вещества вымываются атмосферными осадками, загрязняя окружающую среду. Вместе с тем, золошлаковые отходы являются сырьевой базой, из которой при комплексной переработке можно извлечь такие ценные компоненты, как алюмосиликатные микросферы, магнитную фракцию, редкие и редкоземельные элементы.

В результате обогащения каменного угля образуются следующие виды отходов: порода, промпродукт и флотационный кек. Химический состав минеральной части отходов обогащения угля представлен самыми разнообразными компонентами [1]. Эти компоненты могут использоваться в производстве строительных материалов, в химической и металлургической промышленности для получения концентратов элементов (как самых распространенных, так и редких, рассеянных и благородных металлов). Для оценки возможности утилизации отходов добычи и переработки каменного угля с извлечением ценных компонентов были проведены исследования материалов, предоставленных АО ЦОФ «Березовская».

В таблице 1 представлены результаты исследования отходов обогащения каменного угля марок Ж (производства ООО «Шахта им. С. Д. Тихова») и КО (производства ОАО «УК «Кузбассразрезуголь»). Из полученных данных следует, что промпродукт и кек имеют самую низкую зольность. Данные показатели сравнимы с показателями высокозольного топлива, из чего следует вывод о целесообразности переработки данных отходов в энергетических целях. Порода с тяжелосредного сепаратора и с отсадки, а также флотационные хвосты имеют самую высокую зольность. Содержание угля в данных отходах составляет не более 20 процентов, что не позволяет использовать их в качестве топлива или ресурса для повторного обогащения угля [2,3]. 
Таблица 1

Технический анализ отходов обогащения каменного угля

\begin{tabular}{|c|l|c|c|}
\hline \multirow{2}{*}{$\begin{array}{c}\text { № } \\
\text { п/п }\end{array}$} & \multicolumn{1}{|c|}{ Название пробы } & \multicolumn{2}{|c|}{ Зольность, \% } \\
\cline { 3 - 4 } & & Уголь марки Ж & Уголь марки КО \\
\hline 1 & Порода с тяжелосредного сепаратора & 85.3 & 78.7 \\
\hline 2 & Промпродукт с тяжелосредного сепаратора & 37.7 & 60.0 \\
\hline 3 & Порода с отсадки & 85.3 & 64.4 \\
\hline 4 & Кек с фильтр-прессового отделения & 58.5 & 57.8 \\
\hline 5 & Флотационные хвосты & 80.6 & - \\
\hline
\end{tabular}

C помощью рентгенофлуоресцентного спектрометра SHIMADZU EDX-7000Р был определен химический состав золы, полученной после сжигания образцов отходов. В таблицах 2 и 3 изложены результаты исследования образцов на спектрометре.

Таблица 2

Ценные компоненты золы, полученной

из отходов обогащения каменного угля марки Ж

\begin{tabular}{|c|c|c|c|c|c|}
\hline \multirow{2}{*}{$\begin{array}{c}\text { Минеральный } \\
\text { компонент }\end{array}$} & $\begin{array}{c}\text { Порода с } \\
\text { сепаратора }\end{array}$ & $\begin{array}{c}\text { Промпродукт с } \\
\text { сепаратора }\end{array}$ & $\begin{array}{c}\text { Порода с } \\
\text { отсадки }\end{array}$ & $\begin{array}{c}\text { Кек с } \\
\text { ФПО(масс.) }\end{array}$ & $\begin{array}{c}\text { Флотационные } \\
\text { хвосты }\end{array}$ \\
\cline { 2 - 6 } & \multicolumn{5}{|c|}{} \\
\hline $\mathrm{V}_{2} \mathrm{O}_{5}$ & 0.054 & 0.077 & 0.058 & 0.073 & 0.079 \\
\hline $\mathrm{SrO}$ & 0.037 & 0.121 & 0.035 & 0.093 & 0.106 \\
\hline $\mathrm{ZrO}_{2}$ & 0.029 & 0.022 & 0.030 & 0.031 & 0.034 \\
\hline $\mathrm{Rb}_{2} \mathrm{O}$ & 0.019 & 0.017 & 0.021 & 0.016 & 0.016 \\
\hline $\mathrm{Ir}_{2} \mathrm{O}_{3}$ & 0.007 & 0.007 & 0.007 & 0.006 & 0.007 \\
\hline $\mathrm{Y}_{2} \mathrm{O}_{3}$ & 0.007 & 0.007 & 0.005 & 0.010 & 0.008 \\
\hline $\mathrm{NiO}_{\mathrm{ThO}}$ & 0.007 & 0.013 & 0.009 & 0.006 & 0.005 \\
\hline $\mathrm{Ga}_{2} \mathrm{O}_{3}$ & 0.001 & - & 0.002 & - & 0.001 \\
\hline $\mathrm{Ag}_{2} \mathrm{O}$ & 0.004 & - & 0.004 & - & 0.004 \\
\hline $\mathrm{Tl}_{2} \mathrm{O}_{3}$ & - & - & 0.008 & - & 0.011 \\
\hline $\mathrm{PdO}_{\mathrm{As}} \mathrm{O}_{3}$ & - & - & 0.001 & - & - \\
\hline $\mathrm{NbO}_{\mathrm{MoO}}$ & - & - & - & 0.016 & - \\
\hline & - & - & - & 0.003 & - \\
\hline & - & - & - & 0.003 & - \\
\hline
\end{tabular}


Таблица 3

Ценные компоненты золы, полученной из отходов обогащения каменного угля марки КО

\begin{tabular}{|c|c|c|c|c|}
\hline \multirow{2}{*}{$\begin{array}{c}\text { Минеральный } \\
\text { компонент }\end{array}$} & $\begin{array}{c}\text { Порода с } \\
\text { сепаратора }\end{array}$ & $\begin{array}{c}\text { Промпродукт с } \\
\text { сепаратора } \\
\text { \%(масс.) }\end{array}$ & $\begin{array}{c}\text { Порода с } \\
\text { отсадки }\end{array}$ & Кек с ФПО \\
\hline $\mathrm{V}_{2} \mathrm{O}_{5}$ & 0.031 & 0.043 & 0.053 & 0.064 \\
\hline $\mathrm{SrO}$ & 0.036 & 0.063 & 0.038 & 0.072 \\
\hline $\mathrm{ZrO}_{2}$ & 0.026 & 0.029 & 0.031 & 0.031 \\
\hline $\mathrm{Rb}_{2} \mathrm{O}$ & 0.006 & 0.012 & 0.016 & 0.014 \\
\hline $\mathrm{Ir}_{2} \mathrm{O}_{3}$ & 0.006 & 0.008 & 0.007 & 0.007 \\
\hline $\mathrm{Y}_{2} \mathrm{O}_{3}$ & 0.006 & 0.007 & 0.006 & 0.008 \\
\hline $\mathrm{Ag}_{2} \mathrm{O}$ & 0.006 & 0.002 & 0.004 & 0.004 \\
\hline $\mathrm{NiO}$ & - & 0.009 & 0.009 & 0.001 \\
\hline $\mathrm{ThO}_{2}$ & - & 0.001 & 0.001 & 0.001 \\
\hline $\mathrm{Ga}_{2} \mathrm{O}_{3}$ & - & - & 0.003 & 0.002 \\
\hline $\mathrm{NbO}$ & - & - & 0.001 & 0.001 \\
\hline
\end{tabular}

Химический состав золы представлен, преимущественно, оксидами кремния, алюминия, железа и кальция; в меньшей степени, оксидами магния, калия, натрия, серы, фосфора, титана и марганца. Суммарное содержание этих элементов составляет 99.7-99.8 масс.\%. К ценным компонентам минеральной части отходов углеобогащения относятся редкие, рассеянные и редкоземельные элементы. Их суммарное содержание составляет 0.2-0.3 масс.\%.

Результаты выполненных исследований позволяют сделать следующие выводы:

1. Содержание минеральной части в промпродукте находится в пределах 35.0-60.0 масс.\%, в породе - в пределах 65.0-90.0 масс.\%, во флотационном кеке - в пределах 40.0-60.0 масс.\%. Уменьшение содержания горючей части отходов обогащения каменного угля можно оценить по цепочке «промпродукт с тяжелосредной сепарации - кек с флотации - порода с отсадки - порода с тяжелосредной сепарации». Высокое содержание горючей составляющей в промпродуте и кеке позволяет предполагать их использование в качестве высокозольного топлива. Высокое содержание минеральных компонентов в породе с сепараторов и отсадочных машин не позволяет использовать их в качестве топлива, следует рассматривать возможность использования породы в качестве строительных материалов или же сырья для получения концентратов.

2. Содержание ценных компонентов в отходах обогащения каменного угля составляет не более 0.3 масс.\%. Извлечение ценных компонентов может 
быть целесообразно только как побочный процесс получения концентратов матричных элементов.

\section{Список литературы}

1. Чантурия В. А., Молявко А. Р. Техника и технология обогащения углей. Справочное руководство. Изд. 3-е, перераб. и доп. М.: Наука, 1995. 622 с.

2. Федотов К. В., Никольская Н. И., Власова В. В. Экономические и технологические решения проблемы золоотвалов ТЭС // Горный информационно-аналитический бюллетень (научно-технический журнал). № 8. 2003. C. 234-236.

3. Шпирт, М. Я. Использование твердых отходов добычи и переработки углей // М. Я. Шпирт, В. Б. Артемьев, С. А. Силютин. М.: Горное дело, 2013. $432 \mathrm{c}$.

(C) А.А. Головачев, 2022 